\title{
Impact of Psychological Burden on Marital Life among Diabetic Patients: A Case Study of District Lodhran
}

\author{
Abid Hussain $^{* 1}$, Zareen Atta Memon ${ }^{2}$, Rakhshan Ahsan ${ }^{3}$, and Syeda Khushbakht Hussain ${ }^{4}$ \\ ${ }^{1}$ NPO World Health Organization Multan, Pakistan \\ ${ }^{2}$ Department of Social Work, University of Sindh, Jamshoroo, Pakistan \\ ${ }^{3}$ Home Economics Government Postgraduate College for Women, Sahiwal, Pakistan \\ ${ }^{4}$ Royal College of Health Sciences, Multan, Pakistan \\ *Corresponding Author: drabidwho@yahoo.com
}

\begin{abstract}
The study was accomplished through correlational research design. The purpose was comprised of investigating the impact of psychological burden on patients' level of their marital life. The convenient sampling technique was utilized to approach 139 patients with diabetes mellitus as a sample. The data was collected through questionnaires as a source of measurement. The permission was taken to keep information confidential. The collected data was entered into SPPS for analysing. Inferential statistics were used to test hypothesis with the help of the following tests; linear regression and t-test for independent sample designs. The results of the study reflect that the psychological burden of diabetic patients influences their degree of marital satisfaction significantly. In addition, the difference of psychological burden (stress, depression and anxiety) and marital satisfaction was found significant with respect to demographic characteristics of the participants; gender, type of disease, education and working status. Female patients are reported with a greater level of psychological burden but they were observed with a poor degree of marital satisfaction as compared to males. Psychological burden and satisfaction associated with marital life due to diabetes was discussed as significant between working and non-working, type 1 and type 2 diabetes mellitus, and educated and uneducated patients. In the future, there is a need to investigate the coping styles as mediator between psychological disturbance and marital satisfaction.
\end{abstract}

Keywords: Diabetes, Psychological Burden and Marital Satisfaction

\section{Introduction}

One of the major causes of illness and death in the United States and all around the world is Diabetes mellitus (Carpenter, Theeke, Mallow, Theeke, \& Gilleland, 2017). In the United States alone, there are nearly 29.1 million people with diabetes, which makes up to $9.3 \%$ of the total population. Diabetes is a complicated, weakening disease, which can result in many health issues 
and problems if not dealt with properly. People with diabetes have to make certain changes in their lifestyle and improve their self-managing skills if they want to avoid the known problems and issues that result from diabetes (Coelho, Amorim, \& Prata, 2003).

Doctors and healthcare providers identify hat there are changeable and non-changeable aspects of health that include factors of different environments such as social, physical and financial environment in addition to the individual personality and habits. People having type-2 diabetes mellitus often have to go through known mental of social factors of health at the same time. In the people with diabetes, these factors have been reported to be one of the top ten factors that result in un-well health, which points towards the importance of discussion of these factors for better results (Lee, \& Park, 2019). In general, it has been reported time after time that support from society or family, friends or community is directly related to better results in people with diabetes (Rad, Bakht, Feizi, \& Mohebi, 2013).

\section{Psychological Burden}

Psychological issues like depression, anxiety and other stresses caused by a disease are known to be a problem for people with diabetes. People who have been diagnosed with diabetes have double the risk of getting into depression (Anderson, Freedland, Clouse, \& Lustman, 2001). It is more worrying because it has been reported that people with diabetes and psychological symptoms deal more poorly with these problems than those with no depressive and psychological issues or symptoms. It has been reported that people with type- 2 diabetes had a greater commonness of anxiety as compared to those people who didn't have type-2 diabetes (Smith, Beland, Clyde, Gariepy, Page, Badawi, \& Schmitz, 2013).

Another psychological issue that is different from anxiety but is very real and concerning is diabetes-related stress (Burns, Deschenes, \& Schmitz, 2016), which is the stress that comes from the fear of being diagnosed with type- 2 diabetes. The main cause of this stress is the concern and fear of living in the condition of type-2 diabetes. People with this stress give negative emotional reactions to being diagnosed, like blaming themselves (Burns, Deschenes, \& Schmitz, 2016).

\section{Demographic characteristics and Psychological Burden}

Diabetes mellitus is one of the most common causes of death and sickness and its occurrence is increasing day by day. It is the most common chronic illness in adults. It has been predicted that by year 2025, nearly 300 million people will have diabetes and by the year 2030, nearly 439 million people will have this disease that makes up nearly $7.7 \%$ of the entire world population. It has also been predicted that nearly 3.96 million adults will die due to diabetes each year and this will be responsible for about $6.8 \%$ of all factors that cause death or mortality (King, Aubert, \& Herman, 1998; Shaw, Sicree, \& Zimmet, 2010; Roglic, \& Unwin, 2010).

One of the common health issues that happen in diseases like diabetes is depression (Brown, Majumdar, Newman, \& Johnson, 2005). It has been reported that the occurrence of depression in people with type-2 diabetes is 1.5-2 times higher (Lin, Katon, Von Korff, Rutter, Simon, Oliver, $\&$ Young, 2004). Many studies have shown that there is a link between depressive symptoms and population related, clinical and habitual characteristics in type- 2 diabetes mellitus patients. 
Generally, women, people with low glycemic control, people having insulin therapies or people who have had depression for a longer time had higher rates of depression.

Varying results were found when studies were conducted on the relation between depression and age, education, Body Mass Index (BMI), social status, economic status, smoking and alcohol consumption (1-Amer, Sobeh, Zayed, \& Al-domi, 2011; Lin, Rutter, Katon, Heckbert, Ciechanowski, Oliver, \& Von Korff, 2010). That is why, there has been mixed results about the relation between depression and different demographic and habitual factors within people with type- 2 diabetes mellitus.

\section{Marital satisfaction}

Marital satisfaction is a position where both husband and wife feel comfortable and satisfied with each other and they are happy in their marriage. Satisfaction in a couple's relationship can be measured by their mutual feelings of love, the care they get from each other and their understanding of each other (Dadgari, Mazloom, Abadi, \& Bagheri, 2015). Winch said in Olia that marital satisfaction is the variation of what he or she expected from the marriage to what their current situations and conditions are. Marital satisfaction is not something that just comes out of nowhere and it needs work and effort of both the husband and wife. It has been shown by many studies that marital satisfaction (support from each other) can directly affect a person's health (Kajbaf, Moghaddas, \& Aghaei, 2012). In addition to this, relations have been found between marriage issues and anxiety, depression and poor physical health (Oliya, 2007).

Many psychological, physical and sexual issues have been found in both men and women that were caused by diabetes (Diabetes Control and Complications Trial Research Group, 1993; de Groot, Jacobson, Samson, \& Welch, 1999). Schover (2000) and Wandell and Brorsson (2000) said that after the diagnosis of a chronic disease, relationships may be affected, which causes sexual issues in marriages. The truth is told, marital support plays an important part when it comes to dealing with chronic illness (Coyne, \& Smith, 1994; Primomo, Yates, \& Woods, 1990). The effect of being diagnosed with such an illness is even greater between a couple when one person has to make their way through the diabetes schedule (for instance, buying and cooking food, prescription management, helping with physical exercises and workouts) (Coyne, \& Smith, 1994).

Diabetes may be a cause of sexual issues, which makes it harder to engage in treatment, and may result in problems within the marriage (Lindau, Tang, Gomero, Vable, Huang, Drum, \& Chin, 2010). Sexual issues that are not acknowledged may result in a damaged quality of life and the relationship. Female patients with diabetes, having higher occurrence of sexual relation dysfunction, also showed that they were less satisfied with their marriages, had a poorer quality of life and were found to be at a greater risk of developing depression (Pereira, Marques, Rodrigues, Santos, \& Pedras,2016; Enzlin,, Mathieu, \& Demytteanere, 2003; Enzlin, Mathieu, Van den Bruel, Bosteels, Vanderschueren, \& Demyttenaere, 2002). Pedersen et al. (2015) recently discovered that more often than not, diabetic men and women reported low satisfaction and sexual needs. Hence, it is of great importance that sexual desires and satisfaction get taken into consideration as these have a direct effect on a person's sexual fitness and health (Del Mar Sanchez-Fuentes, Santos-Iglesias, \& Sierra, 2014). 
It is reported in various literature that views about sexual dysfunction are related to less sexual fulfillment (Berg-Cross, 2001).Sexual education plays an important role in diminishing the beliefs in various sexual misconceptions (Kukulu, Gursoy, \& Sozer, 2009), as most of the beliefs related to sexual behaviors and attitudes actually stem from stereotypical ideas about sexuality. Lesser sexual fulfillment has a relation with wrong sexual information or knowledge. In a research about the views and beliefs concerning what is "satisfactory", "wanted" and "too little" or "too much" intra vaginal ejaculatory delay time in those people with sexual dysfunction, the views about dysfunction were related to incapacity, untimely ejaculation and disappointment,

Sexual views and beliefs have a great effect on a person's quality of life and can cause misery and dissatisfaction. Since the expectations about sexual relationships stem from various stereotypes, disappointment because of lack of knowledge may have a direct effect on a person's confidence and quality of life and, thus, can cause emotional suffering as well as problems in the relationship (Owiredu, Amidu, Alidu, Sarpong, \& Gyasi-Sarpong, 2011). Sexual wellness and health when it comes to diabetes is an important topic and is thought to be the incorporation of bodily, emotional, psychological and social factors in a way that provides a constructive and positive education.

World Health Organization (1975), affecting the ways and perceptions people have about their sexualities, is making it a normal thing instead of what people used to refer to as' sexual problems'.Even so, only a few people discuss sexual matters with their family doctors (Lindau Tang, Gomero, Vable, Huang, Drum, \& Chin, 2010). The only research that is known today about the role of views and beliefs about sexual dysfunction and satisfaction in men and women with diabetes showed that women having non-diabetic husbands had a lesser mean score in beliefs about sexual dysfunction as compared to women whose husbands were patients of diabetes (Koolaee, Edalat Asadi, Mosalanejad, \& FathAbadi, 2014).

\section{Marital life satisfaction and Diabetes Mellitus}

People having type-2 diabetes have a greater chance of mood swings than other fit subjects do. Although reports and research about mood swings are different across different studies. Differences might be due to different research methods and diverse circumstances of patients' lives (Malacara, Huerta, Rivera, Esparza, \& Fajardo, 1997; Musselman, Betan, Larsen, \& Phillips, 2003; Nichols, \& Brown, 2003; Fornaro, Iovieno, Clementi, Boscaro, Paggi, Balercia \& Papakostas, 2010). Time after time, women go through psychological and physical symptoms that are linked to the reproductive cycle stage (Sztejnsznajd, da Silva, Nussbacher, Gebara, DAmico, E. A., Rocha, \& Correia, 2006; Huerta, Mena, Malacara, \& de Leon, 1995).Even so, in type-2 diabetic patients, the main connection between mood swings and sex hormone levels is still not understandable.

In both non-diabetic and type- 2 diabetic patients, it is observed that even a short-term diminished sexual activity can prove to be enough to set off depressive symptoms (Schmidt, Berlin, Danaceau, Neeren, Haq Roca, \& Rubinow, 2004). Even so, the study conducted by O'Connor, Archer, \& Wu, 2004), testosterone treatments didn't cause any changes in aggressive, non-aggressive or sexual behavior. The main cause of mood swings that happen in type-2 diabetes is still unknown but there is a high chance that it is very complex and involves various 
social, psychological, hormonal, physical and hereditary factors (Grandjean, \& Moran, 2007).On the other hand, apparent proof of the effects of sex steroids on comprehension and brain activities was reported (Gurvich, Hoy, Thomas, \& Kulkarni, 2018).

i. The perception or comprehension is assisted by Estrogen, which takes action in the prefrontal cortex and the hippocampus by forming bonds through genetic pathways and the supposedly fast non-genetic pathways through the couple proteins, which are bonded with the estrogen receptor and the alpha and betareceptors, are bounded to membranes.

ii. The production of neurotrophins is increased by estrogens, causes the alteration of cholinergic and dopaminergic neurotransmitters, and helps in protection of the brain against inflammation and stress.

iii. The perception or comprehensive functions in the brain are increased by 17Bestradiol which is related to knowledge and memory (studies in animal models). D) In postmenopausal women, 17B-estradiol works in the prefrontal region and develops the perceptive functions, concentration and memory. E) Progesterone has positive and calming effects on the brain, especially in brain development from teenage years to adulthood. F) Both estrogens and progesterone affect neurotic functions, forming connections, promoting bond transmission and have thorough neuroprotective effects. G) In the areas of cognitive functions such as frontal cortex, thalamus, hypothalamus, amygdala, cerebellum and hippocampus, progesterone receptions were found. In addition to this, a constructive relation has been found between Follicle Stimulating Hormone (FSH) and cognition; enhanced cognitive functions have been linked with higher levels of FSH. Hence, it can be safe to say that gonadotropins have a high chance to intervene in cognitive functions (Gurvich, Hoy, Thomas, \& Kulkarni, 2018).

\section{Objectives of the study}

We have following core objective to investigative it.

i. To investigate the impact of Psychological Burden on Marital Satisfaction among patients of Diabetes Mellitus

ii. To know the meaning difference between Psychological Burden and Martial Satisfaction with respect to gender, education, type of diabetes, and working status among patients of Diabetes Mellitus

\section{Hypotheses of the study}

The impact of Psychological Burden would be significant on Marital Satisfaction among patients of Diabetes Mellitus

The mean values of psychological Burden and Marital Satisfaction would be significantly different in relation to demographic variables of patients; gender, education, type of diabetes, and working status 


\section{Research Methodology}

The current study was accomplished through correlational research design. The survey was conducted as a method of data collection, while the participants were selected conveniently from different settings of the public and private health sector in the Multan division. As a sample study, 139 patients with diabetes mellitus were approached and collected data. Demographic information was comprised of the following characteristics; gender, education, type of diabetes mellitus and their working status.

\section{Results}

Table 1: Standard regression model showing impact of psychological burden on marital satisfaction among patients of diabetes mellitus

\begin{tabular}{|c|c|c|c|c|c|}
\hline Predictor & B & Std. Error & Beta & t-test & P-value \\
\hline (Constant) & 117.321 & 4.582 & & 25.602 & .000 \\
\hline PB & -1.274 & .134 & -.631 & -9.511 & .000 \\
\hline
\end{tabular}

$\mathrm{R}^{2}=0.398$, Adjusted $\mathrm{R}^{2}=0.393,(\mathrm{~F}(1,137)=90.456, \mathrm{p}<0.05)$

Table 2: Mean, standard deviation, $t$-value and scores of psychological burden and marital satisfaction with respect to gender $(n=139)$

\begin{tabular}{|c|l|c|c|c|c|c|c|}
\hline Variable & Gender & N & M & Std. Deviation & Df & t-test & P-value \\
\hline \multirow{2}{*}{ Psychological Burden } & Male & 64 & 24.4688 & 9.71493 & 137 & \multirow{2}{*}{-8.425} & \multirow{2}{*}{0.000} \\
& Female & 75 & 38.5067 & 9.85623 & & & \\
\hline \multirow{2}{*}{ Marital Satisfaction } & Male & 64 & 96.7969 & 14.75856 & \multirow{2}{*}{137} & \multirow{2}{*}{14.354} & \multirow{2}{*}{0.000} \\
& Female & 75 & 59.1733 & 15.93091 & & & \\
\hline
\end{tabular}

Table 3: Mean, standard deviation, $t$-value and scores of psychological burden and marital satisfaction with respect to education $(n=139)$

\begin{tabular}{|c|l|l|l|c|l|l|c|}
\hline Variable & Education & $\mathbf{N}$ & $\mathbf{M}$ & Std. Deviation & Df & t-test & P-values \\
\hline Psychological & Educated & 77 & 29.7532 & 10.20340 & 137 & \multirow{2}{*}{2.553} & \multirow{2}{*}{0.012} \\
Burden & Uneducated & 62 & 34.8871 & 13.50301 & & & \\
\hline Marital & Educated & 77 & 77.5195 & 22.57071 & \multirow{2}{*}{137} & \multirow{2}{*}{.552} & \multirow{2}{*}{0.582} \\
Satisfaction & Uneducated & 62 & 75.2258 & 26.39139 & & & \\
\hline
\end{tabular}

Table 4: Mean, standard deviation, t-value and scores of psychological burden and marital satisfaction with respect to types of diabetes mellitus $(n=139)$

\begin{tabular}{|l|l|l|l|c|c|c|c|}
\hline Variable & Type & \multicolumn{1}{l|}{ N } & M & Std.Deviation & Df & t-test & P-value \\
\hline Psychological & Type 1 & 49 & 28.8367 & 10.87686 & 137 & -2.359 & \multirow{2}{*}{0.020} \\
Burden & Type 2 & 90 & 33.7889 & 12.30830 & & & \\
\hline Marital & Type 1 & 49 & 80.5714 & 24.51190 & \multirow{2}{*}{137} & \multirow{2}{*}{1.466} & \multirow{2}{*}{0.145} \\
Satisfaction & Type 2 & 90 & 74.2778 & 24.00563 & & \\
\hline
\end{tabular}


Table 5: Mean, standard deviation, $t$-value and scores of psychological burden and marital satisfaction with respect to working status $(n=139)$

\begin{tabular}{|c|c|c|c|c|c|c|c|}
\hline Variable & Working Status & $\mathbf{N}$ & $\mathbf{M}$ & Std. Deviation & Df & t-test & P-values \\
\hline Psychological & Working & 55 & 28.7818 & 10.66266 & 137 & \multirow{2}{*}{-2.644} & \multirow{2}{*}{0.009} \\
Burden & Non-working & 84 & 34.1786 & 12.43408 & & & \\
\hline Marital & Working & 55 & 80.2364 & 21.79531 & \multirow{2}{*}{137} & \multirow{2}{*}{1.475} & \multirow{2}{*}{0.142} \\
Satisfaction & Non-working & 84 & 74.0476 & 25.61527 & & & \\
\hline
\end{tabular}

\section{Discussion}

Diabetes Mellitus is growing rapidly on a global level with its psychological consequences among patients. The prevalence rate is increasing due to weight gain. Psychological burden (stress, depression and anxiety) is a predictor of poor degree of satisfaction from marital life among the victims of this chronic disease. The findings of the current study reveal that marital satisfaction is positive correlated with psychological burden because stress, depression and anxiety are the predictors of low level of marital satisfaction. Women showed the increased burden of disease related to psychological health as compared to men who were surviving with it. According to gender, the difference was significant in psychological burden and marital satisfaction. Furthermore, the patients who were living with type 2 diabetes showed a higher degree of psychological disturbance and a low level of satisfaction with their life partner as compared to type 1 . Consequently, the non-working and uneducated patients were identified with more psychological problems than working and educated patients.

\section{References}

Al-Amer, R. M., Sobeh, M. M., Zayed, A. A., \& Al-domi, H. A. (2011). Depression among adults with diabetes in Jordan: risk factors and relationship to blood sugar control. Journal of Diabetes and its Complications, 25(4), 247-252.

Anderson, R. J., Freedland, K. E., Clouse, R. E., \& Lustman, P. J. (2001). The prevalence of comorbid depression in adults with diabetes: a meta-analysis. Diabetes care, 24(6), 10691078.

Berg-Cross, L. (2001). Sexuality and the Couple Relationship. Couples Therapy. NY: Press THCP, 357-62.

Brown, L. C., Majumdar, S. R., Newman, S. C., \& Johnson, J. A. (2005). History of depression increases risk of type 2 diabetes in younger adults. Diabetes care, 28(5), 1063-1067.

Burns, R. J., Deschenes, S. S., \& Schmitz, N. (2016). Associations between coping strategies and mental health in individuals with type 2 diabetes: Prospective analyses. Health Psychology, 35(1), 78.

Carpenter, R. D., Theeke, L. A., Mallow, J. A., Theeke, E., \& Gilleland, D. (2017). Relationships among distress, appraisal, self-management behaviors, and psychosocial factors in a 
sample of rural appalachian adults with type 2 diabetes. Online Journal of Rural Nursing and Health Care, 17(2), 34-64.

Coelho, R., Amorim, I., \& Prata, J. (2003). Coping styles and quality of life in patients with noninsulin-dependent diabetes mellitus. Psychosomatics, 44(4), 312-318.

Coyne, J. C., \& Smith, D. A. (1994). Couples coping with a myocardial infarction: Contextual perspective on patient self-efficacy. Journal of Family Psychology, 8(1), 43.

Primomo, J., Yates, B. C., \& Woods, N. F. (1990). Social support for women during chronic illness: The relationship among sources and types to adjustment. Research in Nursing \& Health, 13(3), 153-161.

Dadgari, A., Mazloom, N., Abadi, M. R. H. F., \& Bagheri, I. (2015). The relationship between marital satisfaction and compatibility with type 2 diabetes. Iranian journal of psychiatry and behavioral sciences, 9(4).

de Groot, M., Jacobson, A. M., Samson, J. A., \& Welch, G. (1999). Glycemic control and major depression in patients with type 1 and type 2 diabetes mellitus. Journal of psychosomatic research, 46(5), 425-435.

del Mar Sánchez-Fuentes, M., Santos-Iglesias, P., \& Sierra, J. C. (2014). A systematic review of sexual satisfaction. International journal of clinical and health psychology, 14(1), 67-75.

Diabetes Control and Complications Trial Research Group. (1993). The effect of intensive treatment of diabetes on the development and progression of long-term complications in insulin-dependent diabetes mellitus. New England journal of medicine, 329(14), 977-986.

Education, W. H. O. (1975). treatment in human sexuality: The training of health professionals. World Health Organisation, technical Report Series, (572).

Enzlin, P., Mathieu, C., \& Demytteanere, K. (2003). Diabetes and female sexual functioning: a state-of-the-art. Diabetes Spectrum, 16(4), 256-259.

Enzlin, P., Mathieu, C., Van den Bruel, A., Bosteels, J., Vanderschueren, D., \& Demyttenaere, K. (2002). Sexual dysfunction in women with type 1 diabetes: a controlled study. Diabetes care, 25(4), 672-677.

Fornaro, M., Iovieno, N., Clementi, N., Boscaro, M., Paggi, F., Balercia, G., ... \& Papakostas, G. I. (2010). Diagnosis of co-morbid axis-I psychiatric disorders among women with newly diagnosed, untreated endocrine disorders. The World Journal of Biological Psychiatry, 11(8), 991-996.

Grandjean, C., \& Moran, B. (2007). The impact of diabetes mellitus on female sexual wellbeing. Nursing Clinics of North America, 42(4), 581-592. 


\section{Impact Of Psychological Burden On Marital Life Among Diabetic Patients: A Case Study Of District Lodhran}

Gurvich, C., Hoy, K., Thomas, N., \& Kulkarni, J. (2018). Sex differences and the influence of sex hormones on cognition through adulthood and the aging process. Brain sciences, 8(9), 163.

Huerta, R., Mena, A., Malacara, J. M., \& de León, J. D. (1995). Symptoms at perimenopausal period: its association with attitudes toward sexuality, life-style, family function, and FSH levels. Psychoneuroendocrinology, 20(2), 135-148.

Kajbaf, M. B., Moghaddas, M., \& Aghaei, A. (2012). The effectiveness of neuro-linguistic programming on marital adjustment. Knowl Res Appl Psychol, 12(4), 31-40.

Karlsen, B., Oftedal, B., \& Bru, E. (2012). The relationship between clinical indicators, coping styles, perceived support and diabetes-related distress among adults with type 2 diabetes. Journal of advanced nursing, 68(2), 391-401.

King, H., Aubert, R. E., \& Herman, W. H. (1998). Global burden of diabetes, 1995-2025: prevalence, numerical estimates, and projections. Diabetes care, 21(9), 1414-1431.

Koolaee, A. K., Edalat Asadi, L. M., Mosalanejad, L., \& FathAbadi, A. (2014). A holistic approach to psychological sexual problems in women with diabetic husbands. Iranian Journal of Reproductive Medicine, 12(3), 175.

Kukulu, K., Gürsoy, E., \& Sözer, G. A. (2009). Turkish university students’ beliefs in sexual myths. Sexuality and Disability, 27(1), 49-59.

Lee, K. S., \& Park, K. W. (2019). Social Determinants of Association among Diabetes Mellitus, Visual Impairment and Hearing Loss in a Middle-Aged or Old Population: ArtificialNeural-Network Analysis of the Korean Longitudinal Study of Aging (20142016). Geriatrics, 4(1), 30.

Lin, E. H., Katon, W., Von Korff, M., Rutter, C., Simon, G. E., Oliver, M., ... \& Young, B. (2004). Relationship of depression and diabetes self-care, medication adherence, and preventive care. Diabetes care, 27(9), 2154-2160.

Lin, E. H., Rutter, C. M., Katon, W., Heckbert, S. R., Ciechanowski, P., Oliver, M. M., ... \& Von Korff, M. (2010). Depression and advanced complications of diabetes: a prospective cohort study. Diabetes care, 33(2), 264-269.

Lindau, S. T., Tang, H., Gomero, A., Vable, A., Huang, E. S., Drum, M. L., ... \& Chin, M. H. (2010). Sexuality among middle-aged and older adults with diagnosed and undiagnosed diabetes: a national, population-based study. Diabetes care, 33(10), 2202-2210.

Malacara, J. M., Huerta, R., Rivera, B., Esparza, S., \& Fajardo, M. E. (1997). Menopause in normal and uncomplicated NIDDM women: physical and emotional symptoms and hormone profile. Maturitas, 28(1), 35-45. 
Musselman, D. L., Betan, E., Larsen, H., \& Phillips, L. S. (2003). Relationship of depression to diabetes types 1 and 2: epidemiology, biology, and treatment. Biological psychiatry, 54(3), 317-329.

Nichols, G. A., \& Brown, J. B. (2003). Unadjusted and adjusted prevalence of diagnosed depression in type 2 diabetes. Diabetes care, 26(3), 744-749.

O'connor, D. B., Archer, J., \& Wu, F. C. (2004). Effects of testosterone on mood, aggression, and sexual behavior in young men: a double-blind, placebo-controlled, cross-over study. The Journal of Clinical Endocrinology \& Metabolism, 89(6), 2837-2845.

Oliya, N. (2007). The effect of education enriching couples life on increasing marital satisfaction in Esfahan. Isfahan: University of Isfahan.

Owiredu, W. K., Amidu, N., Alidu, H., Sarpong, C., \& Gyasi-Sarpong, C. K. (2011). Determinants of sexual dysfunction among clinically diagnosed diabetic patients. Reproductive Biology and Endocrinology, 9(1), 70.

Pedersen, M. B., Giraldi, A., Kristensen, E., Lauritzen, T., Sandbæk, A., \& Charles, M. (2015). Prevalence of sexual desire and satisfaction among patients with screen-detected diabetes and impact of intensive multifactorial treatment: Results from the ADDITION-Denmark study. Scandinavian Journal of Primary Health Care, 33(1), 3-10.

Pereira, M. G., Marques, O., Rodrigues, Â., Santos, J., \& Pedras, S. (2016). Sexual Satisfaction in Patients with Diabetes Type 2 and Their Partners. International Journal of Psychology \& Behavior Analysis, 2016.

Rad, G. S., Bakht, L. A., Feizi, A., \& Mohebi, S. (2013). Importance of social support in diabetes care. Journal of education and health promotion, 2.

Roglic, G., \& Unwin, N. (2010). Mortality attributable to diabetes: estimates for the year 2010. Diabetes research and clinical practice, 87(1), 15-19.

Schmidt, P. J., Berlin, K. L., Danaceau, M. A., Neeren, A., Haq, N. A., Roca, C. A., \& Rubinow, D. R. (2004). The effects of pharmacologically induced hypogonadism on mood in Healthy Men. Archives of general psychiatry, 61(10), 997-1004.

Schover, L. R. (2000). Sexual problems in chronic illness. Principles and practice of sex therapy. New York: Guilford, 398, 422.

Shaw, J. E., Sicree, R. A., \& Zimmet, P. Z. (2010). Global estimates of the prevalence of diabetes for 2010 and 2030. Diabetes research and clinical practice, 87(1), 4-14.

Smith, K. J., Béland, M., Clyde, M., Gariépy, G., Pagé, V., Badawi, G., ... \& Schmitz, N. (2013). Association of diabetes with anxiety: a systematic review and meta-analysis. Journal of psychosomatic research, 74(2), 89-99. 
Sztejnsznajd, C., da Silva, M. E. R., Nussbacher, A., Gebara, O. E., D'Ámico, E. A., Rocha, D. M., ... \& Correia, M. R. S. (2006). Estrogen treatment improves arterial distensibility, fibrinolysis, and metabolic profile in postmenopausal women with type 2 diabetes mellitus. Metabolism, 55(7), 953-959.

Wändell, P. E., \& Brorsson, B. (2000). Assessing sexual functioning in patients with chronic disorders by using a generic health-related quality of life questionnaire. Quality of Life Research, 9(10), 1081-1092. 